\title{
Symptomatic postictal cardiac asystole in a young patient with partial seizures
}

\author{
M. Seeck ${ }^{1,2}$, O. Blanke ${ }^{1,2}$, P. Jallon ${ }^{1}$, F. Picard ${ }^{1}$ and S. Zaim ${ }^{3}$ \\ ${ }^{1}$ Department of Neurology, University Hospital of Geneva; ${ }^{2}$ Laboratory of Presurgical Epilepsy Evaluation, \\ Program of the Neurological and Neurological Services of University Hospitals Lausanne and Geneva; \\ ${ }^{3}$ Division of Cardiology, University Hospital of Geneva, Switzerland
}

This report describes a patient with complex partial seizures arising from the right temporal lobe who developed symptomatic sinus arrest following the end of his seizure activity. A ventricular pacemaker was implanted and was documented to function appropriately, preventing development of bradycardia associated symptoms during subsequent seizures. Possibly relevant cerebral structures are briefly discussed.
(Europace 2001; 3: 247-252)

(C) 2000 The European Society of Cardiology

Key Words: Partial seizure, epilepsy, asystole, pacemaker, cardiac arrhythmias, temporal lobe epilepsy.

\section{Introduction}

It has been appreciated for some time that significant cardiac arrhythmias may occur during epileptic seizure activity. Sinus tachycardia is the most common arrhythmia observed but severe bradycardias due to sinus node arrest have also been described ${ }^{[1-12]}$. We describe a patient who presented with a protracted episode of symptomatic sinus node arrest that began in the postictal phase of a complex partial epileptic seizure and which was subsequently prevented by implantation of a permanent ventricular pacemaker.

\section{Case report}

A 28-year-old male with a 12 year history of frequent partial seizures but otherwise in good health was admitted to our neurology laboratory for evaluation of surgical resection of the epileptic focus. His MRI showed a

Manuscript submitted 12 July 2000, and accepted after revision 22 April 2001.

Correspondence: Sina Zaim, M.D., Division de Cardiologie, Hôpital Cantonal, Rue Micheli-du-Crest 24, Geneva CH-1211, Switzerland. E-mail: szaimmd@hotmail.com small cystic lesion in right basal temporal neocortex, most likely a dysembryoblastic neuroepithelial tumor. His witnessed seizures were all psychomotor in nature with occasional verbal automatisms, lip smacking, and manual automatisms, sometimes evolving into tonicclonic seizures. Because the disorder was refractory to several first-line antiepileptic medications, surgical treatment was considered. The patient therefore underwent withdrawal of his antiepileptic agent while under continuous simultaneous video, EEG and ECG monitoring as well as direct observation by a nurse. The sinus rate increased from 60/min at EEG-onset of the seizure (Fig. 1A) to $102 / \mathrm{min}$ by $20 \mathrm{~s}$ to a maximum of $126 / \mathrm{min}$ at $46 \mathrm{~s}$ after EEG-onset (Fig. 1B), while the right temporal activity became more and more distinct. Eight seconds after the EEG-termination of the seizure (61 s after ictal EEG-onset) the patient's heart rate abruptly slowed and sinus arrest, without an escape rhythm, was observed for the subsequent $31 \mathrm{~s}$ (Fig. 1C). Several junctional beats then appeared followed by sinus tachycardia at $102 / \mathrm{min}$ (Fig. 1D) . Tonic-clonic activity developed shortly after the onset of the sinus arrest but stopped quickly after return to sinus rhythm. A ventricular pacemaker was implanted the next day and programmed to VVI mode $50 \mathrm{bpm}$, with a hysteresis rate of $40 \mathrm{bpm}$. Four days after the pacemaker implant and under identical monitoring conditions, the patient had a recurrence of his 


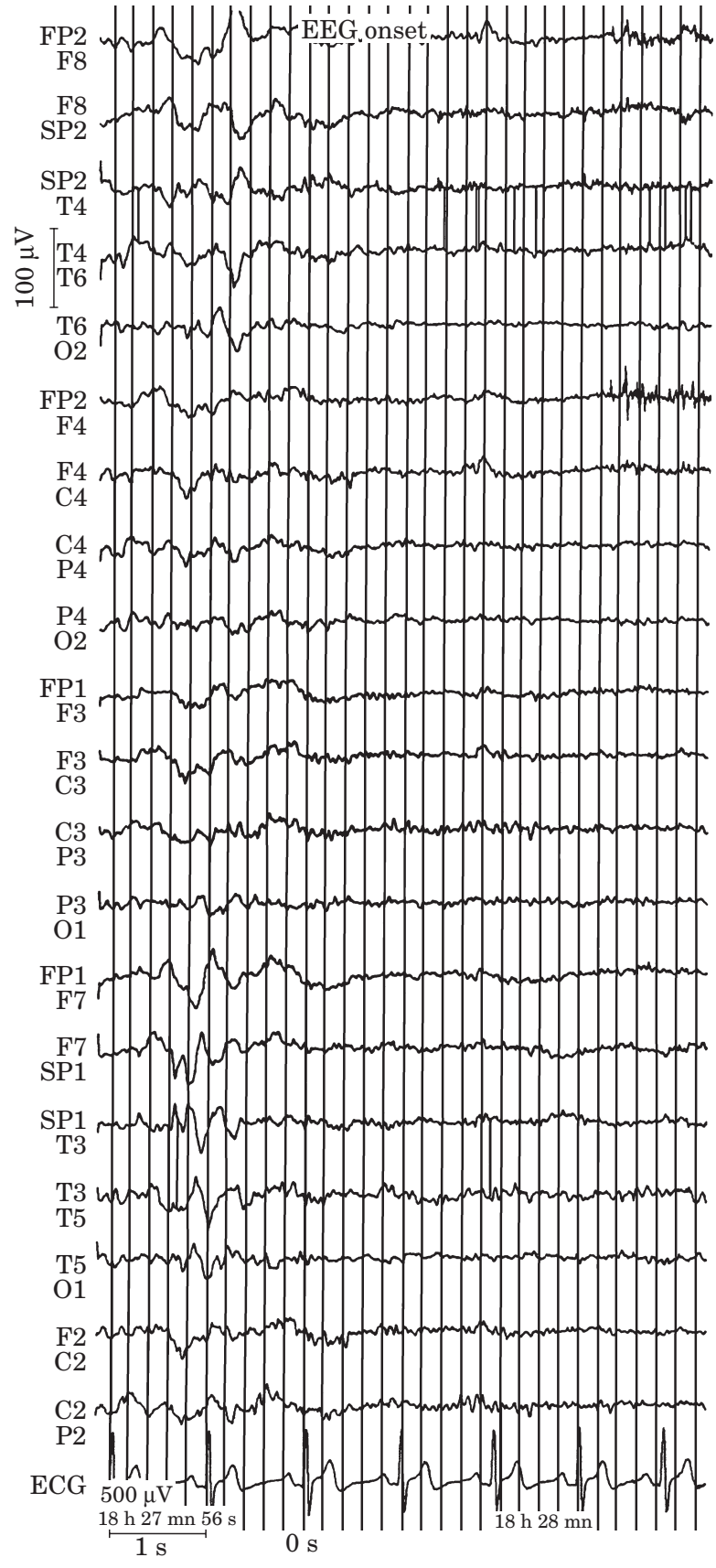

A

seizure and again developed sudden sinus bradycardia $9 \mathrm{~s}$ after EEG-termination of seizure activity (60 s after ictal EEG-onset). The pacemaker began to pace appropriately at that point until recovery of an adequate sinus rate $9 \mathrm{~s}$ later (Fig. 2). No tonic-clonic activity was

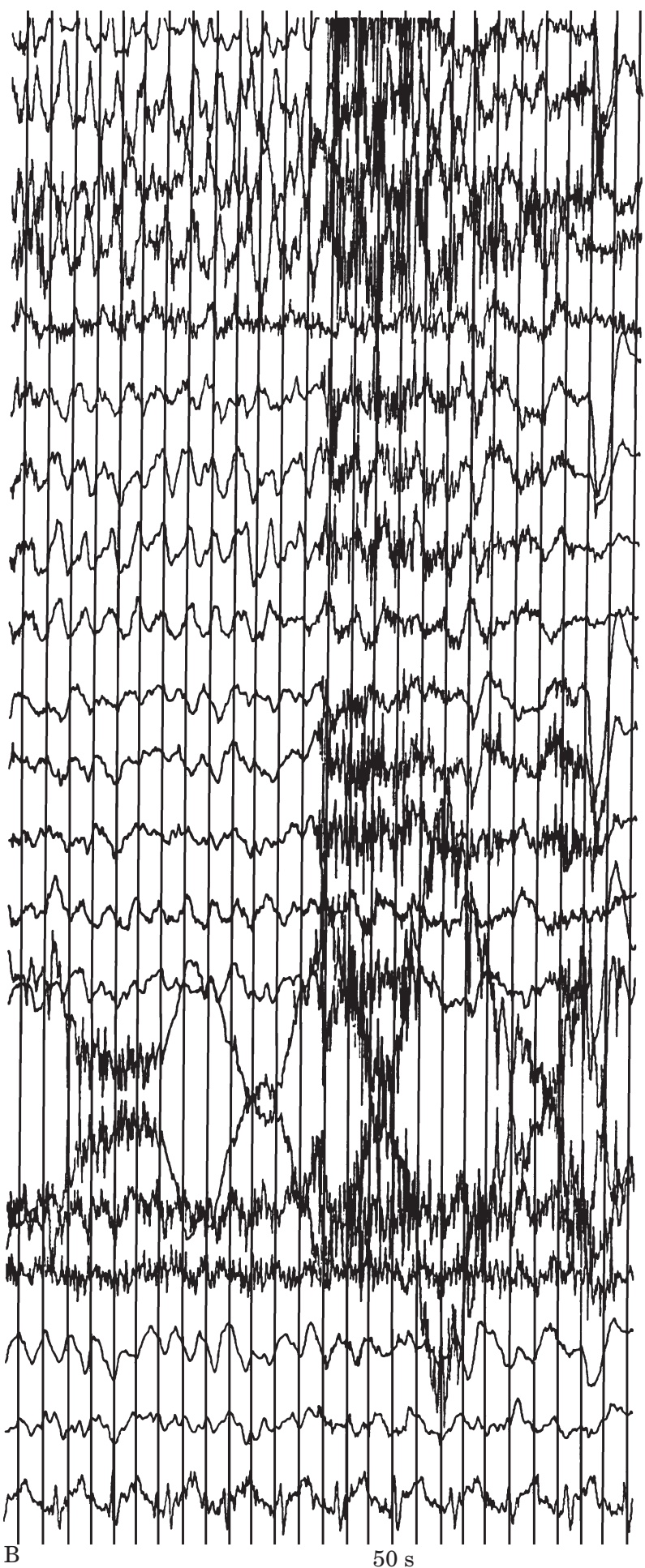

Figure $1 A$ and $B$. observed during this seizure. Despite the right temporal lesion and localization of most seizures to the right temporal lobe, the presurgical work-up (neuropsychological exam, nuclear imagery, MRI, invasive EEGmonitoring with foramen ovale electrodes) revealed 


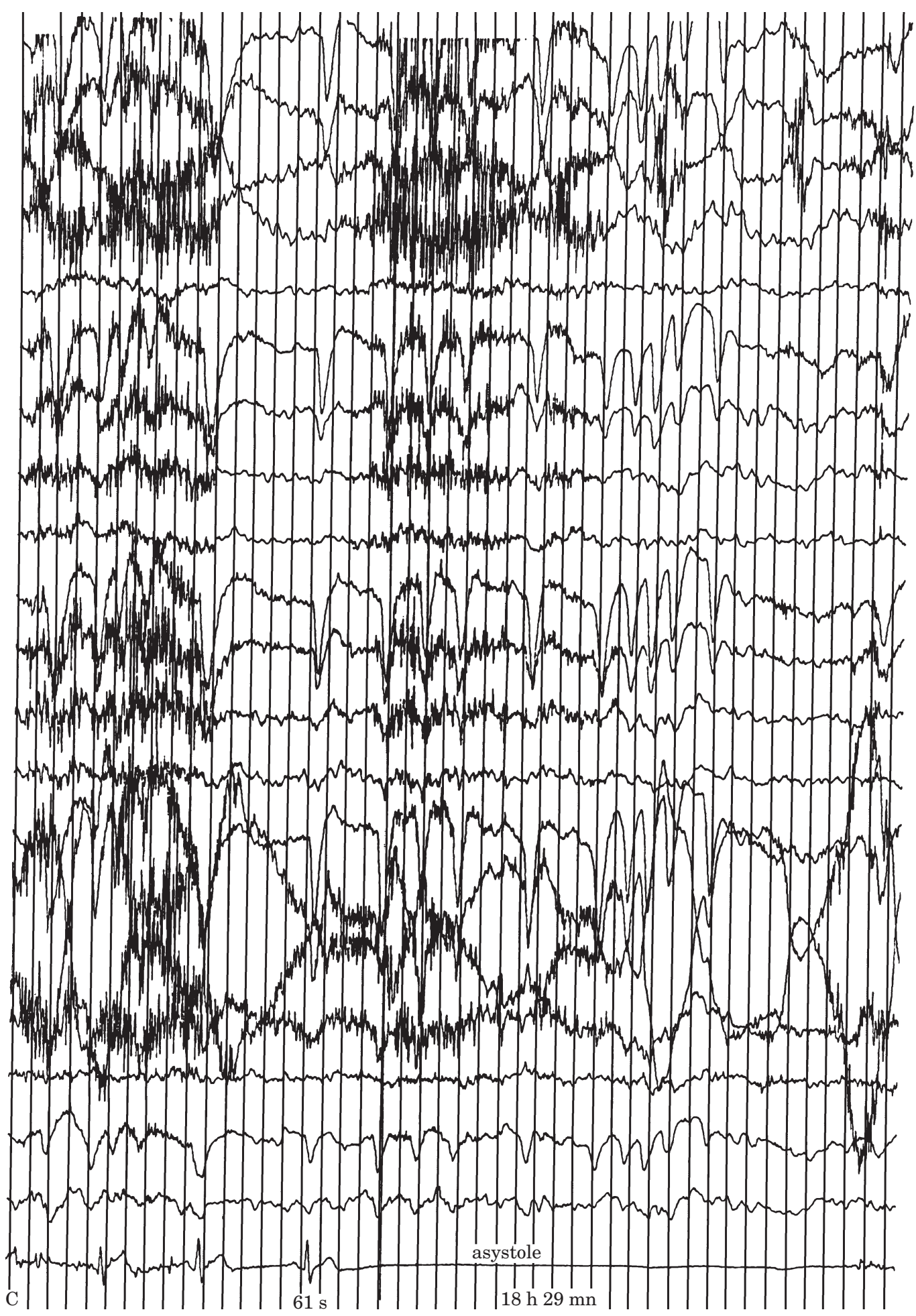

Figure $1 C$.

significant bitemporal dysfunction underlying the partial epilepsy in this patient. A 24-hour ambulatory ECG recording obtained after the patient's discharge, on antiepileptic treatment and without occurrence of epileptic seizures, showed normal sinus rhythm with a mean rate of $76 / \mathrm{min}$, a maximum rate of $147 / \mathrm{min}$ and a minimum rate of $52 / \mathrm{min}$. The patient has had recurrences of his partial seizures but has remained free of postictal tonic-clonic activity during the 6 months following his pacemaker implantation. 


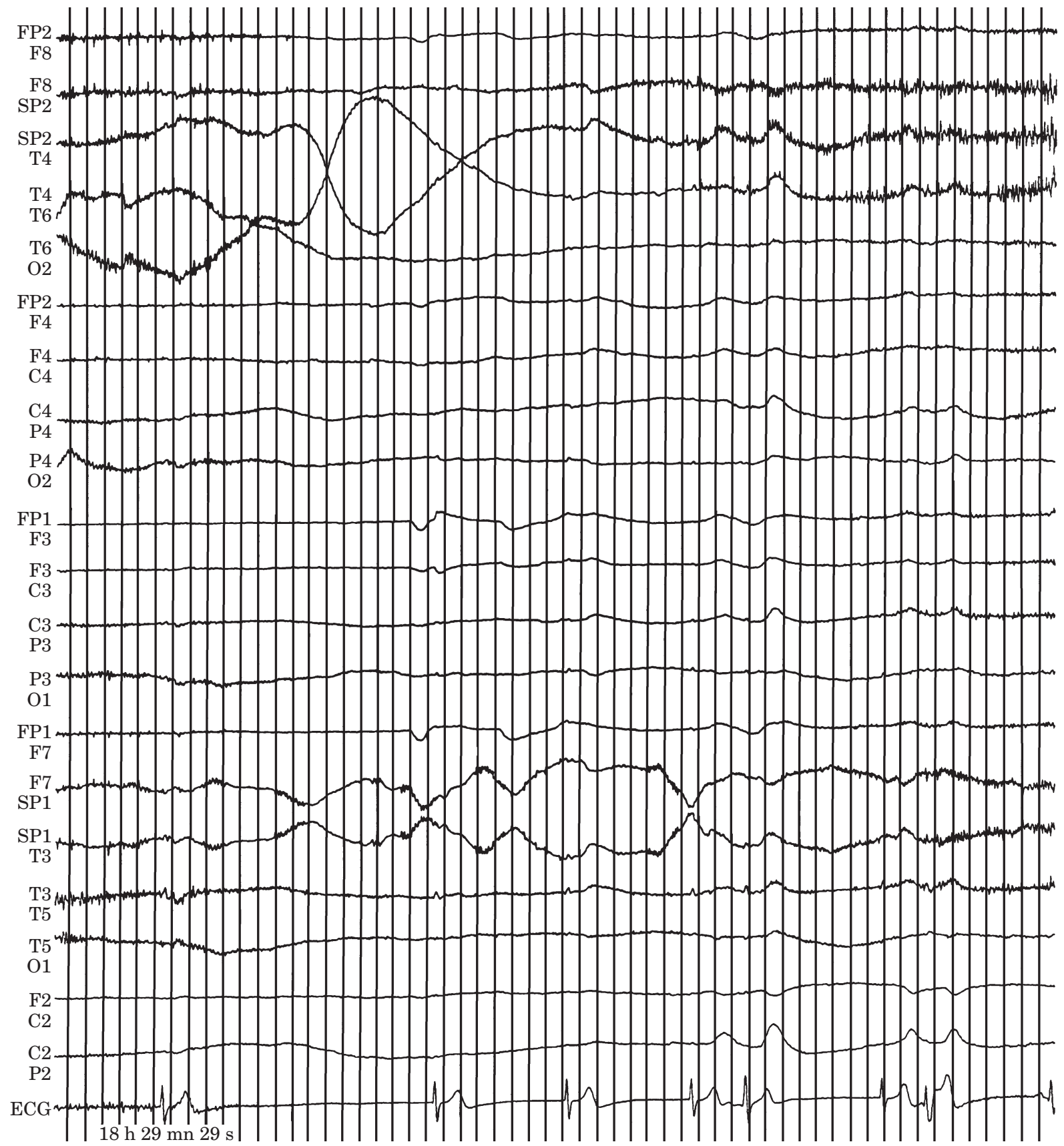

$\mathrm{D}$

Figure $1 D$.

Figure 1A EEG-onset of patient's seizure which eventually led to asystole. Note the abrupt generalized flattening at '0s'. EEG-montage indicated to the left. ECG tracing on the bottom. 1B. EEG tracing $50 \mathrm{~s}$ into the seizure. Theta rhythms $(4 \mathrm{~Hz})$ are predominantly over the right temporal region. In the ECG, sinus tachycardia becomes apparent. $1 C .8 \mathrm{~s}$ after EEG-offset. EEG shows discrete right temporal postictal slowing and motion artefacts. In the ECG one notes onset of asystole at the $61 \mathrm{~s}$ mark. 1D. ECG shows return of cardiac rhythm with junctional beats followed by sinus rhythm. The EEG is characterized by the disappearance of physiological brain activity.

\section{Discussion}

Our patient suffered from drug refractory partial seizures that resulted in severe symptomatic sinus arrest - an infrequent finding. Additionally, this case is unique in that the sinus arrest appears after the end of all EEG-seizure activity whereas onset of sinus arrest in the previously described cases, cited in the references, occurred simultaneously with or soon after onset of the seizure. Consistent with previous clinical observations, 


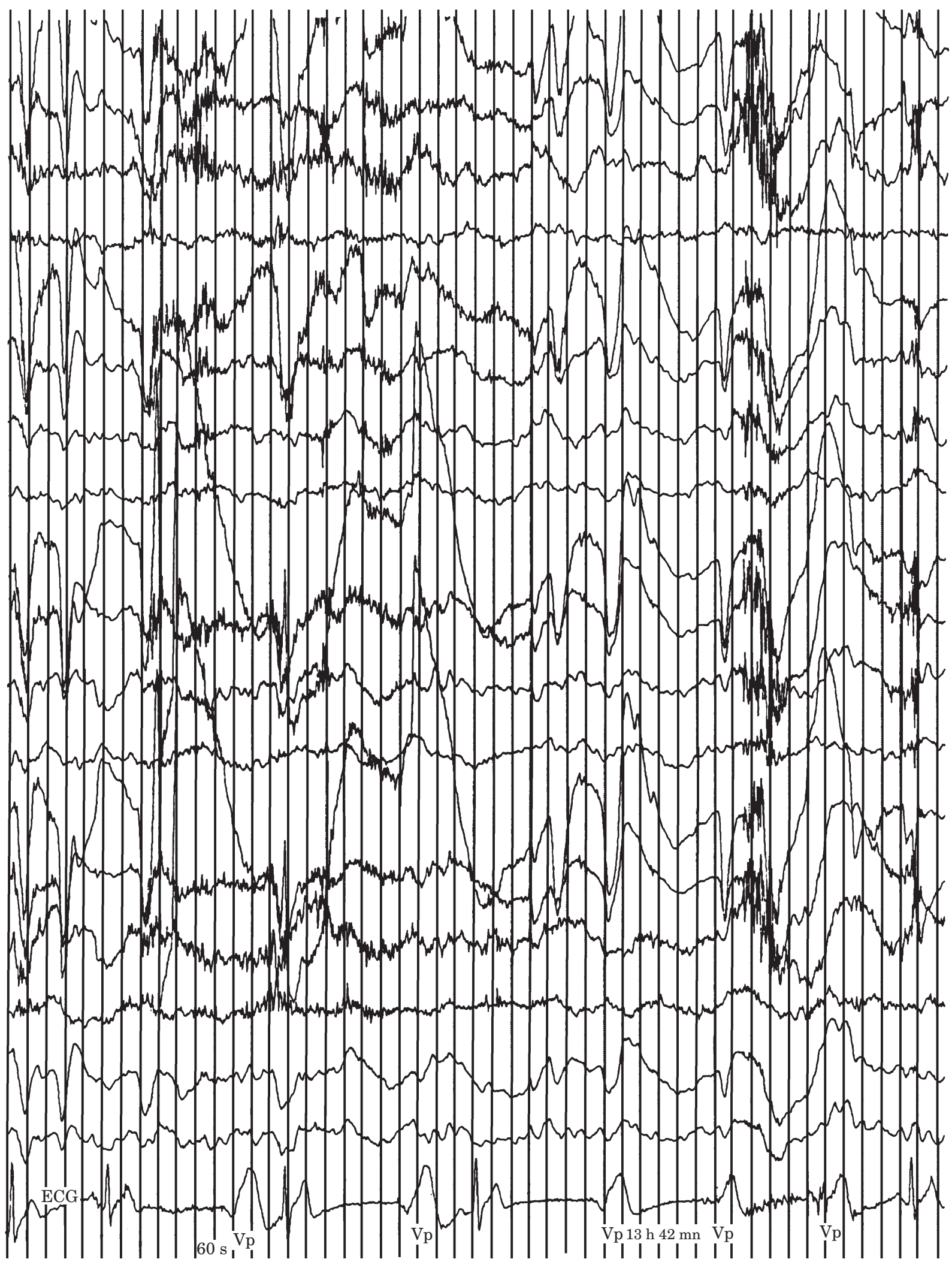

Figure 2 Postictal period (60 s after EEG onset; $9 \mathrm{~s}$ after EEG-offset) of a partial seizure of the same patient, after (VVI) pacemaker implantation, with appropriate ventricular pacing following the onset of severe sinus bradycardia. The EEG shows diffuse slowing with motion artifacts. Vp: ventricular pacing. 
typical EEG changes such as generalized attenuation of the background activity were seen approximately $9 \mathrm{~s}$ following asystole and cessation of cerebral circulation (Fig. 1D) $^{[13]}$.

The beneficial effect of the permanent pacemaker in this patient was clearly documented by the recordings obtained during a subsequent seizure where the pause due to post-seizure sinus arrest was prevented, as well as the continued absence of tonic-clonic movements during the subsequent 6 months despite recurrence of partial seizures during that time.

The involved pathways by which epileptic seizures lead to a cardiac arrhythmia are not clear. Reports of well-documented cases noted that the large majority of such epilepsies are of temporal lobe origin ${ }^{[1,8]}$. Most reports have not found a significant lateralization of the focus although a preponderance of right temporal epilepsy was noted by one investigator (and also is present in our patient $)^{[1,8]}$. Conversely, electrical stimulation of the left insular cortex in patients undergoing epilepsy surgery has been found to be associated more frequently with bradycardia compared with right-sided stimulation $^{[14]}$. However, despite the close proximity of the insular cortex to the temporal lobe structures most patients with temporal lobe epilepsy do not experience significant cardiac arrhythmias thus implying the presence of a complicated interaction between the temporal lobes and/or insular cortices in both hemispheres.

In conclusion, permanent ventricular or even dual chamber pacing may be required in this select group of patients with refractory temporal lobe epilepsy with associated symptomatic sinus bradycardia or asystole in whom the epilepsy cannot be completely controlled. Furthermore, only simultaneous EEG and ECG recording will reveal a possible cerebral origin of arrhythmias in these patients who are, typically, young.
Dr M. Seeck is supported by grants SNF 3100-052933.97 and SNF 3100-57112.99.

\section{References}

[1] Jallon P. Arrhythmogenic seizures. Epilepsia 1997; 38: S43-7.

[2] Blumhart LD, Smith PEM, Owen L. Electrographic accompaniments of temporal lobe epileptic seizures. Lancet 1986; 1: 1051-5.

[3] Locatelli ER, Varghese JP, Shuaib A, et al. Cardiac asystole and bradycardia as a manifestation of left temporal lobe complex partial seizure. Ann Intern Med 1999; 130: 581-3.

[4] Devinsky O, Pacia S, Tatambhotla G. Bradycardia and asystole induced by partial seizures: A case report and literature review. Neurology 1997; 48: 1712-4.

[5] Fincham RW, Shivapour ET, Leis AA, Martins JB. Ictal bradycardia with syncope: A case report. Neurology 1992; 42: 2222-3.

[6] Constantin L, Martins JB, Fincham RW, et al. Bradycardia and syncope as manifestations of partial epilepsy. J Am Coll Cardiol 1990; 15: 900-5.

[7] Liedholm LJ, Gudjonsson O. Cardiac arrest due to partial epileptic seizures. Neurology 1992; 42: 824-9.

[8] Reeves AL, Nollet KE, Klass DW, Sharbrough FW, So EL. The ictal bradycardia syndrome. Epilepsia 1996; 37: 983-7.

[9] Jacome DE, Seroppian ER. Ictal bradycardia. Am J Med Sci 1988; 295: 469-71.

[10] van Rijckevorsel K, Saussu F, de Barsy T. Bradycardia, an epileptic ictal manifestation. Seizure 1995; 4: 237-9.

[11] Wilder-Smith E, Wilder-Smith A. Komplex-partielle Anfälle als Ursache passagerer Herzrhythmusstörungen. Schweiz Med Wochenschr 1995; 125: 2237-43.

[12] Rugg-Gunn F, Duncan JS, Smith SJM. Epileptic cardiac asystole. J Neurol Neurosurg Psychiatry 2000; 68: 108-10.

[13] Clute HL, Levy WJ. Electroencephalographic changes during brief cardiac arrest in humans. Anesthesiology 1990; 73: $821-5$.

[14] Oppenheimer SM, Gelb A, Girvin JP, Hachinski VC. Cardiovascular effect of human insular cortex stimulation. Neurology 1992; 42: 1727-32. 